\title{
Tobacco Use Treatment in Primary Care Patients with Psychiatric Illness
}

\author{
Joseph M. Cerimele, MD, Abigail C. Halperin, MD, MPH, and Andrew J. Saxon, MD
}

The prevalence of smoking is higher in patients with psychiatric illness compared with the general population. Smoking causes chronic illnesses, which lead to premature mortality in those with psychiatric illness, is associated with greater burden of psychiatric symptoms, and contributes to the social isolation experienced by individuals with psychiatric disorders. Most patients with a psychiatric illness present initially to primary care rather than specialty care settings, and some patients receive care exclusively in the primary care setting. Therefore, family physicians and other primary care clinicians have an important role in the recognition and treatment of tobacco use disorders in patients with psychiatric illnesses. In this article we review common myths associated with smoking and psychiatric illness, techniques for implementing evidence-based tobacco use treatments, the evidence base for tobacco use treatment for patients with specific psychiatric diagnoses, and factors to consider when treating tobacco use disorders in patients with psychiatric illness.(J Am Board Fam Med 2014;27:399-410.)

\section{Keywords: Mental Disorders, Tobacco Use Cessation}

Tobacco use is common among patients with psychiatric disorders. ${ }^{1}$ While smoking prevalence among the general adult population is $20 \%$, almost one half of patients with bipolar disorder and two thirds of patients with schizophrenia seen in clinical settings smoke, ${ }^{2}$ and the decline in smoking prevalence in the United States that has occurred among the general population has not occurred in the population with psychiatric illness ${ }^{3}$ Furthermore, tobacco use disorders occur in one third to one half of patients with common psychiatric illnesses such as major depressive disorder, posttraumatic stress

This article was externally peer reviewed.

Submitted 6 September 2013; revised 13 January 2014; accepted 21 January 2014.

From the Department of Psychiatry and Behavioral Sciences (JMC), the Department of Family Medicine (ACH), School of Medicine, and the Department of Health Services, School of Public Health (ACH), University of Washington, Seattle; and the Veteran's Affairs Puget Sound Health Care System, Seattle, WA (AJS).

Funding: JMC is supported by a grant from the National Institute of Mental Health (T-32 MH020021-16).

Conflict of interest: AJS has served on the scientific advisory board for Alkermes, Inc., and as a speaker for ReckittBenckiser, Inc.

Corresponding author: Joseph M. Cerimele, MD, Department of Psychiatry and Behavioral Sciences, University of Washington School of Medicine, 1959 NE Pacific St., Box 356560, Seattle, WA 98195 (E-mail: cerimele@uw.edu). disorder (PTSD), or 1 of 3 anxiety disorders (generalized anxiety disorder, social anxiety disorder, and panic disorder). ${ }^{4}$ Smokers with psychiatric illness also consume more cigarettes per day compared with smokers without psychiatric illness. ${ }^{5}$ Consequently, between $31 \%$ to $44 \%$ of all cigarettes in the United States are smoked by individuals with psychiatric illnesses, which occur in about $20 \%$ of the population annually. ${ }^{4,6}$

Chronic diseases caused by smoking, such as hypertension and chronic obstructive pulmonary disease, are more common among patients with psychiatric illness compared with those without psychiatric disorders. ${ }^{7,8}$ In addition, such chronic illnesses generally occur earlier in life in these patients, leading to a greater degree of illness-related disability and impairment. ${ }^{9}$ Unfortunately, the life expectancy of people with psychiatric illnesses such as schizophrenia and bipolar disorder is approximately 10 to 20 years less than the general population, largely because of premature deaths from smoking-related illnesses. ${ }^{10-12}$

The disparity in tobacco use between individuals with and without psychiatric illness is present in primary care settings as well. In one study, primary care patients with psychiatric disorders were twice as likely to be current smokers compared with those 
without psychiatric illness $(41.1 \%$ vs $19.5 \% ; P=$ .002). ${ }^{13}$ Family physicians are well positioned to initiate tobacco use treatment for patients with psychiatric illness since most of these patients initially present in primary care settings. ${ }^{14}$ Furthermore, national efforts by the Centers for Disease Control and Prevention encouraging smokers to ask their doctors about smoking will likely lead to more patients initiating discussions with primary care doctors about their cigarette use. ${ }^{15}$ Many patients with common psychiatric conditions such as depression are treated by primary care physicians without referral to specialty mental health care providers, and patients who smoke generally prefer receiving tobacco use treatment in their primary care clinic. ${ }^{16}$ Based on patients' service utilization and preferences, the primary care setting may be the only opportunity many patients with psychiatric illness have to receive tobacco use treatment.

Despite the known negative consequences of smoking, clinicians often feel uncomfortable addressing tobacco use with patients in general, and this is particularly true when patients have psychiatric diagnoses. ${ }^{12}$ Primary care physicians' efforts to treat tobacco use in patients with psychiatric illness can be enhanced by dispelling common myths and misperceptions about why patients with psychiatric disorders smoke and by improving knowledge of evidence-based treatment options.

This article is a narrative review of the treatment of tobacco use disorders in primary care patients with psychiatric illnesses. We identified relevant articles for this review by searching PubMed, the Cochrane database, and GoogleScholar. We also searched the reference lists of key articles for additional relevant reports. We will not cover the research examining tobacco use treatment in patients with substance use disorders because of our intent to focus on other psychiatric illnesses such as depression and bipolar disorder.

\section{Myths about Psychiatric Illness and Smoking}

Prochaska ${ }^{17}$ described 5 myths associated with clinicians' reluctance to provide tobacco use treatment to patients with psychiatric illness. First is that patients with psychiatric illness smoke for "necessary self-medication." ${ }^{17}$ Six studies prospectively measured associations between smoking and psychiatric symptom severity over at least 6 months in patients with bipolar disorder or schizophrenia who smoked compared with patients who did not smoke. ${ }^{18}$ Five studies showed that those who smoked cigarettes experienced higher symptom burden, as evidenced by more frequent suicidal thoughts, ${ }^{19}$ higher severity of negative symptoms of schizophrenia ${ }^{20}$ and bipolar disorder, ${ }^{21}$ higher rates of alcohol and cannabis use, ${ }^{21,22}$ and a greater number of days spent in a psychiatric hospital. ${ }^{21}$ These findings are consistent with evidence showing that use of other addictive substances, such as alcohol, is associated with higher psychiatric symptom burden, greater treatment resistance, and greater risk of relapse in patients with co-occurring psychiatric illness substance use. ${ }^{23}$

The second myth is that "people with mental illness are not interested in quitting smoking." Smokers with psychiatric illness are just as likely as smokers without psychiatric illness to express interest in quitting smoking. ${ }^{17}$ For example, among more than 500 current smokers with bipolar disorder, approximately three-quarters reported wanting to quit smoking, consistent with the rate among the general population. ${ }^{24}$ In addition, patients with bipolar disorder had a median of 4 prior quit attempts, suggesting that individuals remained interested in quitting despite prior unsuccessful attempts.

The third myth listed by Prochaska ${ }^{17}$ is that "mentally ill people cannot quit smoking." Several systematic reviews and meta-analyses ${ }^{1,25-29}$ have shown that, when treated with appropriate tobacco use treatments, patients with psychiatric illness can achieve abstinence from cigarettes at a rate only slightly lower than patients without psychiatric illness. $^{5}$

The fourth myth describes the belief that "quitting smoking interferes with recovery from mental illness." ${ }^{17}$ Research suggests that smoking cessation does not interfere with psychiatric illness treatment and may actually improve treatment outcomes. ${ }^{17,28}$ For example, $\mathrm{McF}$ all et $\mathrm{al}^{30}$ showed that initiating tobacco use treatment concurrently with PTSD treatments was associated with greater prolonged abstinence and no worsening in symptoms of PTSD. In addition, smokers with baseline anxiety or depressive disorder who continued smoking were more likely to have major depression (odds ratio [OR], $1.97 ; 95 \%$ confidence interval [CI], 1.003-3.85) or a substance use disorder (OR, 2.51; 95\% CI, 1.135.56) at 3-year follow-up compared with individuals who quit smoking. ${ }^{31}$ 
The final myth is that smoking cessation is a low priority for patients with psychiatric symptoms. Clinicians treating patients with psychiatric illness often encounter competing demands such as cooccurring general medical, substance use, and psychosocial problems. However, for patients with psychiatric illness, smoking causes chronic illnesses and premature mortality, ${ }^{11}$ contributes to social isolation and financial stress, ${ }^{5}$ and is associated with poor nutrition ${ }^{32}$ and higher psychiatric symptom burden. ${ }^{18}$ As such, clinicians should consider smoking and its consequences as high-priority clinical problems.

\section{General Treatment Principles}

The US Public Health Service (USPHS) clinical practice guideline by Fiore and Baker ${ }^{33}$ comprehensively describes the evidence and proven techniques for clinical management of tobacco use disorders. Two subsequent review articles describe updates in evidence-based clinical practice. ${ }^{34,35}$ Much of the discussion below draws from these key resources. The principles of smoking cessation apply equally to the treatment of smokers with and without psychiatric illness. We briefly review 5 categories of tobacco use treatment principles and practice: addressing nicotine withdrawal, case identification and counseling, enhancing motivation to quit, medications for smoking cessation, and telephone quit lines.

\section{Nicotine Withdrawal}

Abrupt cessation or reduction in nicotine consumption results in a withdrawal syndrome characterized by irritability, sleep problems, dysphoria, lowered frustration tolerance, impaired concentration, restlessness, increased appetite, lowered heart rate, and cigarette cravings. ${ }^{36}$ These symptoms may last up to 4 weeks, with most patients experiencing a higher intensity of symptoms during the first week of abstinence. ${ }^{37}$ Primary care physicians can help patients understand the nicotine withdrawal syndrome and offer treatment with nicotine replacement therapy, other approved cessation medications, and/or behavioral coping strategies to alleviate the discomfort caused by nicotine withdrawal. ${ }^{37}$

Nicotine withdrawal symptoms can mimic symptoms of patients' primary psychiatric illnesses, such as major depression and generalized anxiety disorder. ${ }^{35}$ Because nicotine withdrawal symptoms are lessened with exposure to nicotine (ie, when smoking a cigarette), many patients and clinicians believe that cigarettes treat psychiatric symptoms when in fact resuming smoking is only lessening the symptoms of nicotine withdrawal. ${ }^{12,36}$ In addition, patients with psychiatric illnesses may experience more severe nicotine withdrawal symptoms. Since greater severity of nicotine withdrawal symptoms is associated with smoking relapse, it is important to help patients accurately recognize symptoms of nicotine withdrawal and to offer treatments for it. $33,35,38,39$

\section{Case Identification and Counseling}

Almost three quarters of smokers attend at least one primary care appointment per year. ${ }^{34}$ Enhancing recognition of smokers in primary care is important so that effective treatments can be initiated for patients who are motivated to quit smoking and strategies to increase motivation can be used for patients who are not ready to quit. ${ }^{34}$ The 2008 USPHS clinical practice guideline ${ }^{33}$ recommends using the 5 As technique for case identification and treatment (Ask about tobacco use; Advise to quit; Assess willingness to make a quit attempt; Assist in a quit attempt; Arrange follow-up). One way to incorporate the 5 As into clinical practice is to ask each patient about smoking while measuring vital signs and record smoking status as a vital sign. ${ }^{40}$ The primary care clinician then will be able to implement the remaining 4 As for those patients answering "yes" to the question about current tobacco use.

A large effectiveness trial involving 2325 patients in 9 primary care clinics showed that clinicians in routine practice tended to use only the first 2 As (Ask and Advise) more often than all 5 As. $^{41}$ However, patients receiving treatment using the 5 As were more likely to quit smoking (OR, 1.82; 95\% CI, 1.16-2.86 for counseling and OR, 2.23; 95\% CI, 1.56-3.2 for pharmacotherapy), arguing for the importance of using all 5 components.

\section{Enhancing Motivation to Quit}

Approximately $30 \%$ of smokers report not being interested in quitting smoking, ${ }^{42}$ and patients who say they want to stop smoking often have mixed feelings about making a quit attempt. ${ }^{34}$ Enhancing motivation to quit is thus a critical part of tobacco use treatment and can be done 
using motivational interviewing (MI), an evidence-based approach used to address patients' ambivalence about behavior change. Expressing empathy, developing discrepancy, rolling with resistance, and supporting self-efficacy are key strategies in $\mathrm{MI} .{ }^{33} \mathrm{MI}$ has been shown to be effective in treating tobacco dependence both alone and in combination with medication. A Cochrane review ${ }^{43}$ showed that MI significantly increased abstinence from smoking at 6 months compared with usual care or brief advice (relative risk [RR], 1.27; 95\% CI, 1.14-1.42).

In addition to MI, the 2008 USPHS clinical practice guideline ${ }^{33}$ recommends using the 5 Rs technique to enhance motivation, whereby patients are asked to identify the personal Relevance of quitting smoking, the short- and long-term Risks of continued smoking, the Rewards of quitting smoking, and the anticipated Roadblocks to quitting. The clinician should Repeat these techniques each time the smoker is seen in the clinic until he or she has successfully quit. ${ }^{33}$

\section{Smoking Cessation Medications}

All patients should be encouraged to use counseling and pharmacotherapy since the combination is more effective than either intervention alone. ${ }^{33}$ Seven first-line pharmacological agents have been approved by the Food and Drug Administration (FDA) for tobacco use treatment, including 2 nonnicotine medications (bupropion and varenicline) and 5 forms of nicotine replacement (patch, gum, lozenge, nasal spray, and inhaler). ${ }^{33-35}$ Two second-line agents (clonidine and nortriptyline) have evidence supporting their effectiveness in tobacco use treatment but do not have FDA indications. ${ }^{33}$ Patients' odds of achieving abstinence are approximately doubled when using any of these 7 medications during a quit attempt. ${ }^{33-35}$ Adding counseling to medication treatment increases abstinence rates by approximately $50 \%$ over medication treatment alone. ${ }^{33}$

Three preparations of nicotine replacement (patch, gum, lozenge) are sold over the counter, and 2 preparations are prescription only (inhaler and nasal spray). ${ }^{35}$ Patients using any of the nicotine replacement products, including over-thecounter products, should be counseled on appropriate use since many misperceptions about nicotine replacement exist. The transdermal patch delivers nicotine slowly over 24 hours and must be replaced daily.
Heavy smokers may require more than one patch to achieve relief from nicotine withdrawal and often benefit from combining the patch with a fasteronset and shorter-duration form of nicotine replacement (the nicotine gum, lozenge, inhaler, or nasal spray), which are generally dosed several times daily. Combination treatment with the nicotine patch plus nicotine lozenge, where the patch is applied daily and the lozenge is used as needed, resulted in the highest abstinence rates compared with 4 other treatment options in 2 trials. ${ }^{44,45}$

In a randomized controlled trial that largely excluded individuals with psychiatric illness, the combination of varenicline and bupropion was superior to varenicline alone in producing prolonged abstinence rates at 12 and 26 weeks but not at 52 weeks. ${ }^{46}$ A recent analysis of 17 clinical trials involving more than 8000 patients showed that use of varenicline was not associated with adverse neuropsychiatric events, ${ }^{47}$ although a black box warning from 2009 advises clinicians to assess for adverse neuropsychiatric events in patients taking varenicline. Additional information on each of the 7 FDA-approved medications is shown in Table 1.

\section{Tobacco Quitlines}

Telephone quitlines provide effective treatment for tobacco dependence. Current state quitlines (1-800-QUIT-NOW) connect individuals with counselors who deliver phone-based interventions and assist callers with finding local clinicians who can provide tobacco use treatment. ${ }^{48}$ In addition, many states offer fax referral systems for clinicians to refer patients directly to a quitline, and some states also offer nicotine replacement therapy. A large trial of 3282 smokers showed that quitlines delivering a protocol-based smoking cessation intervention of up to 7 phone sessions approximately doubled quit rates (6month abstinence, $11.7 \%$ vs $5.2 \%$ ) compared with quitlines delivering self-help materials and information about smoking. ${ }^{49}$ One study showed that quitline callers with major depression could achieve abstinence at 2 months, although a lower percentage of callers with depression achieved 2-month abstinence compared with callers without depression $(18.5 \%$ vs $28.4 \%) .^{50}$ 


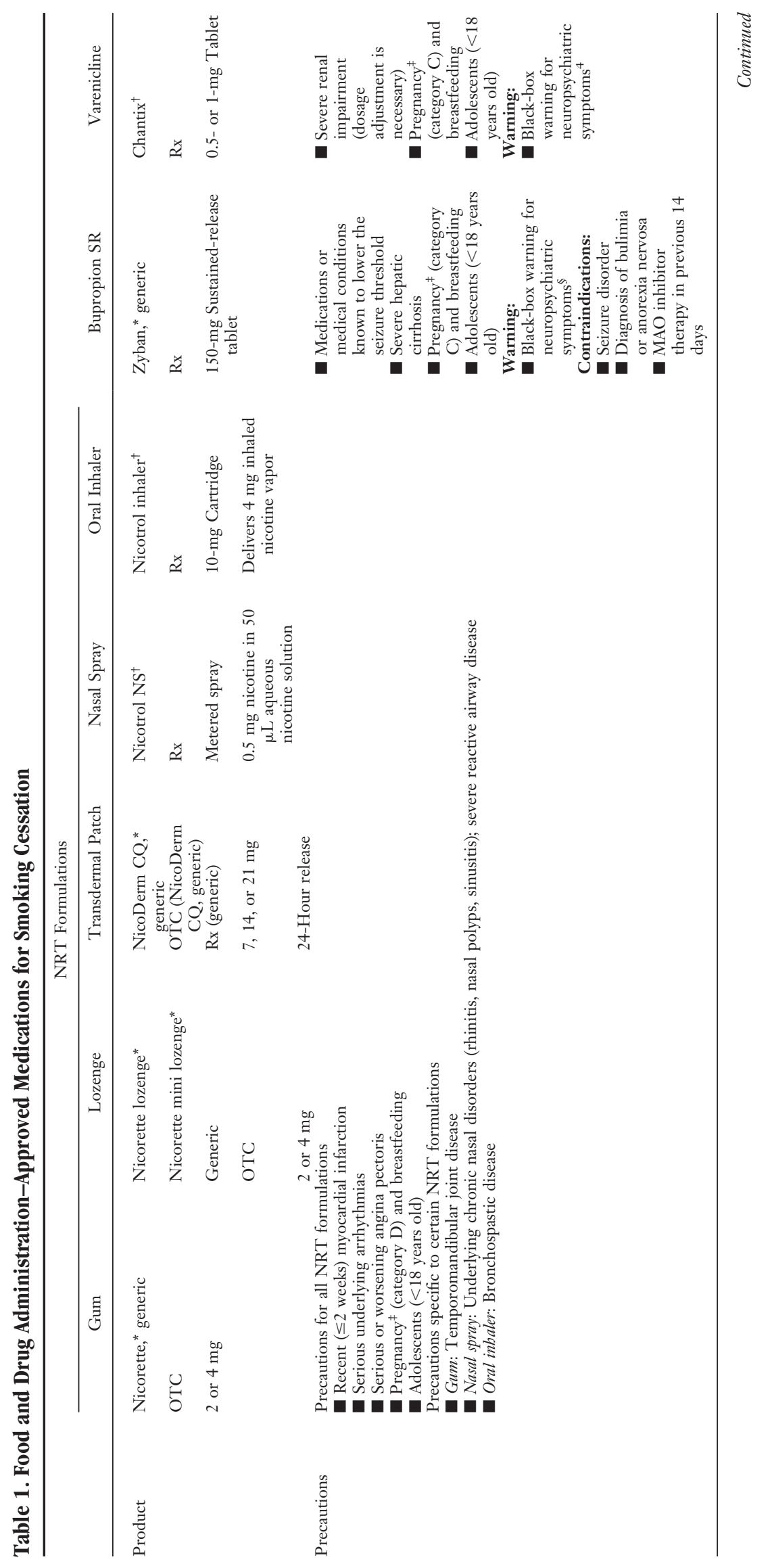




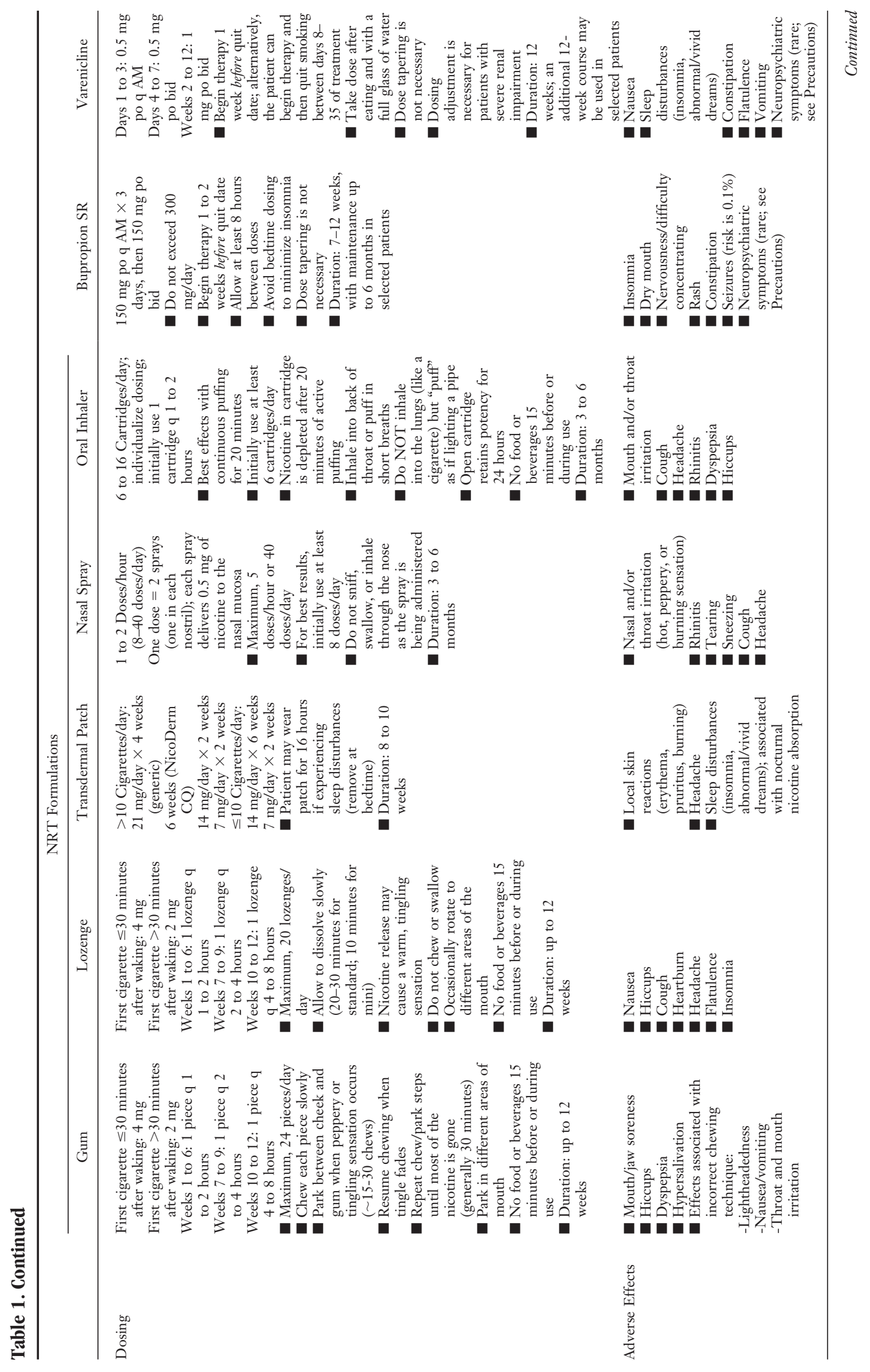




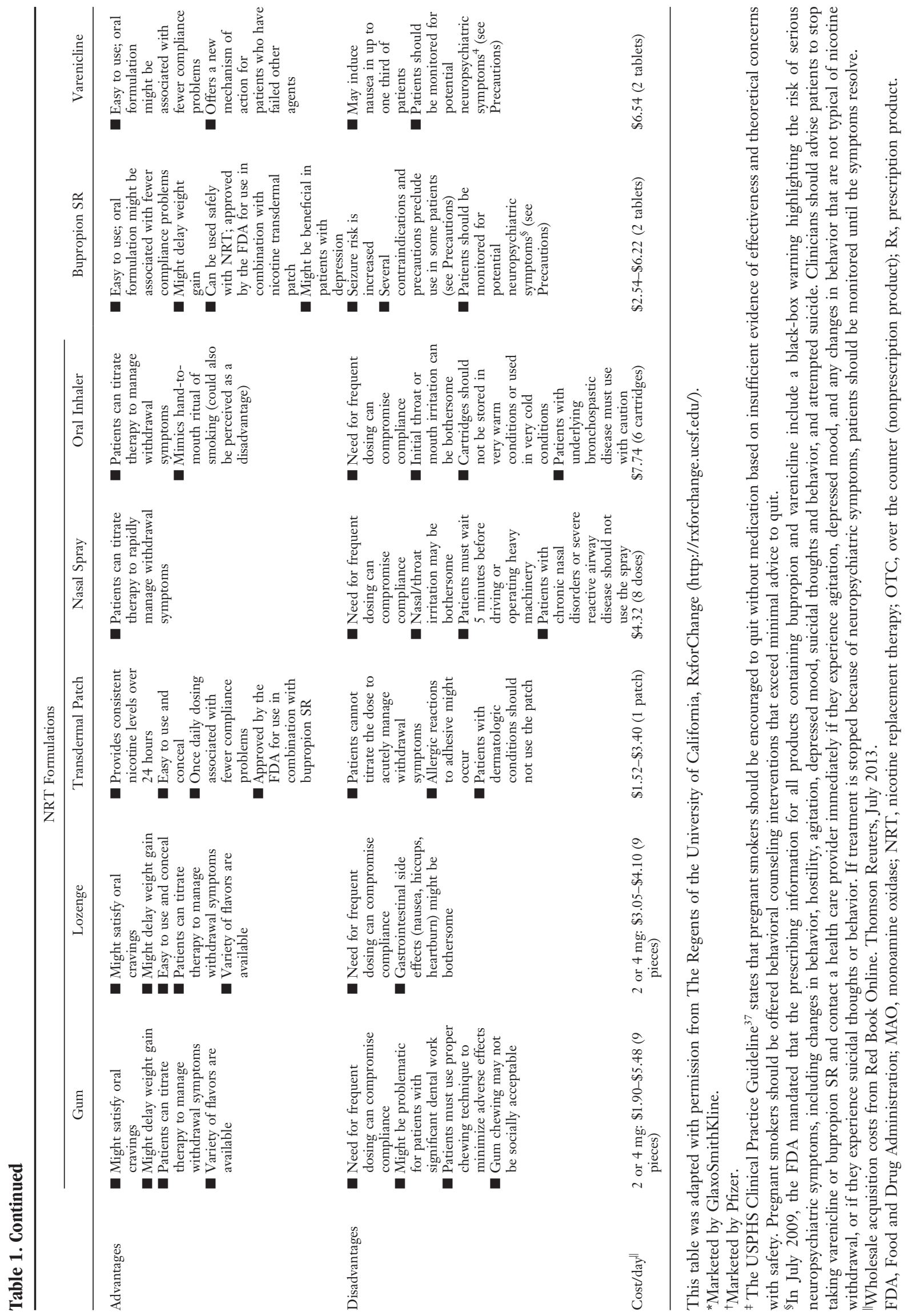




\section{Tobacco Use Treatment in Patients with Psychiatric Illness \\ Major Depression}

Early studies showed that while patients with depression who are receiving treatment for tobacco dependence could successfully quit smoking, the incidence of depressive symptoms or a depressive episode was increased in patients who achieved cessation. ${ }^{51-54}$ Until recently, many clinicians hesitated to offer tobacco use treatment to patients with major depression because of concerns that cessation would cause a depressive episode.

Current evidence shows that patients with depression should be offered tobacco use treatment since smoking may actually worsen depressive symptoms. Longitudinal studies have shown that smoking increases the risk of depressive symptoms ${ }^{55}$ and the incidence of mood and anxiety disorders ${ }^{56}$; that current heavy smoking is strongly associated with current depression ${ }^{57}$; and that current smoking strongly predicts depression recurrence. ${ }^{58}$ In addition, a trial of tobacco use treatment in patients with current depression showed that depressive symptoms were not worse in patients who successfully quit smoking compared with those who continued to smoke. ${ }^{59,60}$ Another study showed that smokers who did not successfully quit smoking experienced a higher severity of depression symptoms compared with those who successfully quit. ${ }^{61} \mathrm{~A}$ recent randomized clinical trial showed that 12 weeks of treatment with varenicline in adults $(\mathrm{n}=525)$ with past or current treated major depression doubled the odds of quitting during 52 weeks of follow-up and that no worsening of depression, anxiety, suicidal ideation, or other neuropsychiatric occurred in the varenicline or placebo groups. $^{62}$

A Cochrane review ${ }^{63}$ showed that use of bupropion increased long-term cessation in smokers with past depression and that adding a mood management intervention to standard tobacco use treatment further increased abstinence rates in patients with current depression.

\section{Anxiety Disorders and PTSD}

Smoking during adolescence was associated with the onset of adulthood anxiety disorders in a large epidemiologic study. ${ }^{64}$ Consistent with this finding, the prevalence of current smoking among adults with anxiety disorders is approximately $35 \%$ to $45 \%$, nearly double that of the general population. ${ }^{4}$ Despite the bidirectional association between anxiety disorders and smoking, few clinical trials have tested tobacco use treatment in patients with anxiety disorders. ${ }^{28}$

As noted earlier, the intervention tested by McFall et $\mathrm{al}^{30}$ doubled the rate of 12 -month prolonged abstinence (OR, 2.26; 95\% CI, 1.3-3.91) in veteran smokers with PTSD. This was achieved using a well-tolerated combination of educational and behavioral skills sessions and medications, including varenicline, bupropion, and nicotine replacement therapy.

\section{Bipolar Disorder and Schizophrenia}

Although approximately half of patients with bipolar disorder smoke, few trials have assessed tobacco use treatment in this population. ${ }^{2,65}$ Two small ( $\mathrm{n}=5$ for both studies) randomized controlled trials of tobacco use treatment in patients with bipolar disorder showed that bupropion ${ }^{66}$ and varenicline ${ }^{67}$ did not worsen psychiatric symptoms. In addition, the total number of cigarettes smoked per day was reduced in the varenicline group compared with placebo, ${ }^{67}$ and patients randomized to bupropion stopped smoking. ${ }^{66}$ A subsequent proofof-concept study by Heffner et $\mathrm{al}^{68}$ showed that a mood management intervention plus a nicotine patch resulted in 2 of 9 patients achieving tobacco abstinence and 7 of 9 patients achieving at least $50 \%$ reduction in daily cigarette consumption over 8 weeks. A recent large clinical trial of 203 patients with either bipolar disorder or schizophrenia showed that varenicline is efficacious for tobacco use treatment and presents no safety risks in this population. $^{69}$

A Cochrane review ${ }^{70}$ showed that in 7 trials, bupropion, compared with placebo, was associated with a 3 -fold higher cessation rate at the end of the trials (RR, 3.03; 95\% CI, 1.69-5.42), a result that endured for 6 months in 5 of the trials (RR, 2.78; $95 \%$ CI, 1.02-7.58). ${ }^{70}$ Varenicline use also was associated with significantly higher cessation rates compared with placebo in 2 trials with 137 patients (RR, 4.74; 95\% CI, 1.34-16.71). ${ }^{70}$ Psychiatric symptoms were not worsened in patients receiving bupropion or varenicline. ${ }^{26,70}$ Although individual trials have shown increased cessation rates for patients with schizophrenia who used nicotine replacement, the Cochrane review analysis did not find evidence of a significant benefit. ${ }^{70}$ 


\section{Other Considerations}

Electronic cigarettes have recently received much attention, and one randomized trial suggests that use of electronic cigarettes may lead to abstinence rates similar to those seen with transdermal nicotine replacement. ${ }^{71}$ However, concerns exist about the safety, regulation, content, and marketing of electronic cigarettes, including mixed evidence regarding use of e-cigarettes as a cessation aid, high levels of dual use with tobacco cigarettes, and the potential "renormalization" of smoking through advertising and public use of electronic cigarettes. ${ }^{72}$

There are several special considerations in the treatment of tobacco use in patients with psychiatric illness (Table 2). The aromatic hydrocarbons in tobacco smoke induce CYP P450 enzymes that metabolize several psychotropic medications such as clozapine, olanzapine, and haloperidol. ${ }^{73}$ Thus

Table 2. Special Considerations When Treating Smoking in Patients with Psychiatric Illness

\begin{tabular}{|c|c|}
\hline Consideration & Comment \\
\hline $\begin{array}{l}\text { Tobacco smoke-medication } \\
\text { interactions }\end{array}$ & $\begin{array}{l}\text { Tobacco smoke, but not nicotine, } \\
\text { induces the metabolism of } \\
\text { several psychotropic } \\
\text { medications through the } \\
\text { CYP1A2 enzyme. Medication } \\
\text { doses for some psychotropic } \\
\text { medications will need to be } \\
\text { reduced if the patient achieves } \\
\text { abstinence from smoking. }\end{array}$ \\
\hline Nicotine withdrawal & $\begin{array}{l}\text { Symptoms of nicotine } \\
\text { withdrawal, such as irritability, } \\
\text { sleep problems, fatigue, } \\
\text { impaired concentration, and } \\
\text { appetite changes, may mimic } \\
\text { symptoms of psychiatric illness. } \\
\text { Nicotine withdrawal can be } \\
\text { alleviated with nicotine } \\
\text { replacement therapy or with } \\
\text { varenicline to some extent. }\end{array}$ \\
\hline Persistence & $\begin{array}{l}\text { Successful smoking cessation } \\
\text { requires persistent efforts since } \\
\text { most patients require more } \\
\text { than one attempt to quit. } \\
\text { Every attempt to quit provides } \\
\text { opportunities for learning how } \\
\text { to quit, and patients are more } \\
\text { likely to succeed with each } \\
\text { subsequent try. }\end{array}$ \\
\hline $\begin{array}{l}\text { Caffeine-tobacco smoke } \\
\text { interaction }\end{array}$ & $\begin{array}{l}\text { Tobacco smoke also induces the } \\
\text { metabolism of caffeine. } \\
\text { Smoking cessation without a } \\
\text { reduction in caffeine intake } \\
\text { may lead to symptoms of } \\
\text { caffeine toxicity, including } \\
\text { anxiety, restlessness, sleep } \\
\text { problems, and irritability, } \\
\text { which can mimic symptoms of } \\
\text { psychiatric illness. }\end{array}$ \\
\hline
\end{tabular}

current smokers typically need higher doses of some psychotropic medications to attain therapeutic levels, and dosages should be reduced after smoking cessation to avoid potential adverse medication side effects. In addition, treating tobacco use requires persistent efforts by clinicians since most patients require more than one quit attempt to achieve abstinence, despite whether they have a psychiatric disorder. ${ }^{1}$ However, every quit attempt provides opportunities for learning how to quit, and subsequent attempts are more likely to succeed.

\section{Case Example}

A 30-year-old woman with depression and asthma presents to a primary care clinic for an annual examination. During vital sign measurement, the medical assistant asks the patient if she smokes cigarettes, and the patient answers "yes, a pack a day" and that she is "on the fence about quitting." The primary care physician determines that the patient is currently experiencing mild depressive symptoms, evidenced by a 9-item Patient Health Questionnaire score of 8, and moderate asthma symptoms evidenced by exercise intolerance and daily cough. In addition to continuing treatment for asthma and depression, the primary care physician advises the patient to quit smoking, explaining that smoking may be associated with her chronic depressive and asthma symptoms. The physician then assesses the patient's willingness to make a quit attempt. Despite mixed feelings about quitting, the patient states that she does want to make a quit attempt, and says that her main reason for coming to the clinic was "to get help quitting." The physician briefly counsels the patient, encouraging her and reinforcing the message that quitting smoking is the best thing she can do for her health, prescribes varenicline with instructions and precautions, and helps her set a quit date for 1 week later. The physician then refers the patient to the state quitline for telephone support and arranges for the patient to return to the clinic in 10 days for follow-up.

\section{Conclusion}

Tobacco dependence occurs frequently in patients with psychiatric illness, causing chronic illnesses that result in reduced life expectancy. Smoking also is associated with psychiatric symptoms in a sub- 
stantial portion of patients with psychiatric illness, and although nicotine withdrawal syndrome may mimic psychiatric symptoms, withdrawal can be alleviated by behavioral and pharmacological modalities. Effective tobacco dependence treatments are available for patients with psychiatric illness. Reframing tobacco use treatment as a way to reduce overall psychiatric symptom burden and improve the general health of patients with psychiatric illness may help clinicians make tobacco use treatment a higher priority in the care of patients with psychiatric illness.

\section{References}

1. Ziedonis D, Hitsman B, Beckham JC, et al. Tobacco use and cessation in psychiatric disorders: National Institute of Mental Health report. Nicotine Tob Res 2008;10:1691-715.

2. Dickerson F, Stallings CR, Origonia AE, et al. Cigarette smoking among persons with schizophrenia or bipolar disorder in routine clinical settings, 19992011. Psychiatr Serv 2013;64:44-50.

3. LeCook B, Wayne GF, Kafali N, Liu Z, Shu C, Flores M. Trends in smoking among adults with mental illness and association between mental health treatment and smoking cessation. JAMA 2014;311: $172-82$.

4. Lasser K, Boyd W, Woolhandler S, Himmelstein DU, McCormick D, Bor DH. Smoking and mental illness: a population-based prevalence study. JAMA 2000;284:2606-10.

5. Schroeder SA, Morris CD. Confronting a neglected epidemic: tobacco cessation for persons with mental illnesses and substance abuse problems. Annu Rev Public Health 2010;31:297-314.

6. Centers for Disease Control and Prevention (CDC). Vital Signs: current cigarette smoking among adults aged $\geq 18$ years with mental illness-United States, 2009-2011. MMWR Morb Mortal Wkly Rep 2013; 62:81-7.

7. Goff DC, Sullivan LM, McEvoy JP, et al. A comparison of ten-year cardiac risk estimates in schizophrenia patients from the CATIE study and matched controls. Schizophr Res 2005;80:45-53.

8. Himelhoch S, Lehman A, Kreyenbuhl J, et al. Prevalence of chronic obstructive pulmonary disease among those with serious mental illness. Am J Psychiatry 2004;161:2317-9.

9. Katon WJ. Clinical and health services relationships between major depression, depressive symptoms, and general medical illness. Biol Psychiatry 2003;54: 216-26.

10. Roshabaei-Moghaddam B, Katon W. Premature mortality from general medical illnesses among persons with bipolar disorder: a review. Psychiatr Serv 2009;60:174-6.
11. Druss BD, Zhao L, Von Esenwein S, Morrato EH, Marcus SC. Understanding excess mortality in persons with mental illness: 17-year follow up of a nationally representative US survey. Med Care 2011; 49:599-604.

12. Schroeder SA. A 51-year-old woman with bipolar disorder who wants to quit smoking. JAMA 2009; 301:522-31.

13. Daumit GL, Pratt LA, Crum RM, Powe NR, Ford DE. Characteristics of primary care visits for individuals with severe mental illness in a national sample. Gen Hosp Psychiatry 2002;24:391-5.

14. Wang PS, Lane M, Olfson M, Pincus HA, Wells KB, Kessler RC. Twelve month use of mental health services in the United States: results from the $\mathrm{Na}$ tional Comorbidity Survey Replication. Arch Gen Psychiatry 2005;62:629-40.

15. McAfee T. Encouraging smokers to talk with their physicians about quitting. JAMA 2013;309:2329-30.

16. Fiore MC, McCarthy DE, Jackson TC, et al. Integrating smoking cessation treatment into primary care: an effectiveness study. Prev Med 2004; 38:412-20.

17. Prochaska JJ. Smoking and mental illness-breaking the link. N Engl J Med 2011;365:196-8.

18. Cerimele JM, Katon W. Associations between health risk behaviors and symptoms of schizophrenia and bipolar disorder: a systematic review. Gen Hosp Psychiatry 2013;35:16-22.

19. Ostacher MJ, LeBeau RT, Perlis RH, et al. Cigarette smoking is associated with suicidality in bipolar patients. Bipolar Disord 2009;11:766-71.

20. Kotov R, Guey LT, Bromet EJ, Schwartz JE. Smoking severity in schizophrenia: diagnostic specificity, symptom correlates and illness severity. Schiophr Bull 2010;36:173-81.

21. Dodd S, Brnabic AJM, Fitzgerald PB, et al. A prospective study of the impact of smoking on outcomes in bipolar and schizoaffective disorder. Compr Psychiatry 2010;51:504-9.

22. Heffner JL, Delbello MP, Anthenelli RM, et al. Cigarette smoking and its relationship to mood disorder symptoms and co-occurring alcohol and cannabis use disorders following first hospitalization for bipolar disorder. Bipolar Disord 2012;14:99-108.

23. Pettinati HM, Oslin DW, Kampman KM, et al. A double-blind, placebo-controlled trial combining sertraline and naltrexone for treating co-occurring depression and alcohol dependence. Am J Psychiatry 2010;167:668-75.

24. Prochaska JJ, Reyes RS, Schroeder SA, Daniels AS, Doederlein A, Bergeson B. An online survey of tobacco use, intentions to quit, and cessation strategies among people living with bipolar disorder. Bipolar Disord 2011;13:466-73.

25. Banham L, Gilbody S. Smoking cessation in severe mental illness: what works? Addiction 2010;105: $1176-89$. 
26. Cerimele JM, Durango A. Does varenicline worsen psychiatric symptoms in patients with schizophrenia or schizoaffective disorder? A review of published studies. J Clin Psychiatry 2012;73:e1039-47.

27. El-Guebaly N, Cathcart J, Currie S, Brown D, Gloster S. Smoking cessation approaches for persons with mental illness or addictive disorders. Psychiatr Serv 2002;53:1166-70.

28. Hall SM, Prochaska JJ. Treatment of smokers with co-occurring disorders: emphasis on integration in mental health and addiction treatment settings. Annu Rev Clin Psychol 2009;5:409-31.

29. Hitsman B, Borrelli B, McChargue DE, Spring B, Niaura R. History of depression and smoking cessation outcome: a meta-analysis. J Consult Clin Psychol 2003;71:657-63.

30. McFall M, Saxon AJ, Malte CA, et al. Integrating tobacco cessation into mental health care for posttraumatic stress disorder: a randomized controlled trial. JAMA 2010;304:2485-93.

31. Piper ME, Rodock M, Cook JW, Schlam TR, Fiore MC, Baker TB. Psychiatric diagnoses among quitters versus continuing smokers 3 years after their quit day. Drug Alcohol Depend 2013;128:148-54.

32. McCreadie RG. Diet, smoking and cardiovascular risk in people with schizophrenia: descriptive study. Br J Psychiatry 2003;183:534-9.

33. Fiore MC, Jaen CR, Baker TB, et al. Treating tobacco use and dependence: 2008 update. Rockville, MD: US Department of Health and Human Services; 2008.

34. Fiore MC, Baker TB. Treating smokers in the health care setting. N Engl J Med 2011;365:1222-31.

35. Rigotti NA. Strategies to help a smoker who is struggling to quit. JAMA 2012;308:1573-80.

36. Benowitz NL. Nicotine addiction. N Engl J Med 2010;362:2295-303.

37. Hughes JR. Effects of abstinence from tobacco: valid symptoms and time course. Nicotine Tob Res 2007; 9:315-27.

38. Smith PH, Homish GG, Giovino GA, Kozlowski LT. Cigarette smoking and mental illness: a study of nicotine withdrawal. Am J Public Health 2013;104: e127-33.

39. Hughes JR, Gust SW, Keenan RM, Fenwick JW. Symptoms of tobacco withdrawal: a replication and extension. Arch Gen Psychiatry 1991;48:52-9.

40. Fiore MC, Jorenby DE, Schensky AE, Smith SS, Bauer RR, Baker TB. Smoking status as the new vital sign: effect on assessment and intervention in patients who smoke. Mayo Clin Proc 1995;70:209-13.

41. Quinn V, Hollis JF, Smith KS, et al. Effectiveness of the 5-As tobacco cessation treatments in nine HMOs. J Gen Intern Med 2008;24:149-54.

42. Centers for Disease Control and Prevention (CDC). Quitting smoking among adults-United States, 2001-2010. MMWR Morb Mort Wkyl Rep 2011;60:1513-9.
43. Lai DT, Cahill K, Qin Y, Tang JL. Motivational interviewing for smoking cessation. Cochrane Database Syst Rev 2010;1:CD006936.

44. Smith SS, McCarthy DE, Japuntich SJ, et al. Comparative effectiveness of 5 smoking cessation pharmacotherapies in primary care clinics. Arch Int Med 2009; 169:2148-55.

45. Piper ME, Smith SS, Schlam TR, et al. A randomized placebo-controlled clinical trial of 5 smoking cessation pharmacotherapies. Arch Gen Psychiatry 2009;66:1253-62.

46. Ebbert JJO, Hatsukami DK, Croghan IT, et al. Combination varenicline and bupropion SR for tobacco-dependence treatment in cigarette smokers: a randomized trial. JAMA 2014;311:155-63.

47. Gibbons RD, Mann JJ. Varenicline, smoking cessation, and neuropsychiatric adverse events. Am J Psychiatry 2013;170:1460-7.

48. Smokefree.gov [homepage on the Internet]. Washington, DC: U.S. Department of Health and Human Services; 2013. Available from: www.smokefree.gov. Accessed August 1, 2013.

49. Zhu SH, Anderson CM, Tedeschi GJ, et al. Evidence of real-world effectiveness of a telephone quitline for smokers. N Engl J Med 2002;347:1087-93.

50. Hebert KK, Cummins SE, Hernandez S, Tedeschi GJ, Zhu SH. Current major depression among smokers using a state quitline. Am J Prev Med 2011; 40:47-53.

51. Glassman AH, Helzer JE, Covey LS, et al. Smoking, smoking cessation, and major depression. JAMA 1990;264:1546-9.

52. Covey LS, Glassman AH, Stetner F. Major depression following smoking cessation. Am J Psychiatry 1997; 154:263-5.

53. Glassman AH, Covey LS, Stetner F, Rivelli S. Smoking cessation and the course of major depression: a follow-up study. Lancet 2001;357:1929-32.

54. Hughes JR. Depression during tobacco abstinence. Nicotine Tob Res 2006;9:443-6.

55. Boden JM, Fergusson DM, Horwood LJ. Cigarette smoking and depression: tests of causal linkages using a longitudinal birth cohort. Br J Psychiatry 2010; 196:440-6.

56. Mojtabai R, Crum RM. Cigarette smoking and onset of mood and anxiety disorders. Am J Pub Health 2013;103:1656-65.

57. Khaled SM, Bulloch AG, Williams JVS, Hill JC, Lavorato DH, Patten SB. Persistent heavy smoking as risk factor for major depression (MD) incidenceevidence from a longitudinal Canadian cohort of the National Population Health Survey. J Psychiatr Res 2012;46:436-43.

58. Colman I, Naicker K, Zeng Y, Ataullahjan A, Senthilselvan A, Patten SB. Predictors of long-term prognosis of depression. CMAJ 2011;183:1969-76.

59. Hall SM, Tsoh JY, Prochaska JJ, et al. Treatment for cigarette smoking among depressed mental health 
outpatients: a randomized clinical trial. Am J Pub Health 2006;96:1808-14.

60. Prochaska JJ, Hall SM, Tsoh JY, et al. Treating tobacco dependence in clinically depressed smokers: effects of smoking cessation on mental health functioning. Am J Pub Health 2008;98:446-8.

61. Berlin I, Chen H, Covey LS. Depressive mood, suicide ideation and anxiety in smokers who do and smokers who do not manage to stop smoking after a target quit day. Addiction 2010;105:2209-16.

62. Anthenelli RM, Morris C, Ramey TS, et al. Effects of varenicline on smoking cessation in adults with stably treated current or past major depression. Ann Intern Med 2013;159:390-400.

63. van der Meer R, Willemsen MC, Cuijpers P. Smoking cessation interventions for smokers with current or past depression. Cochrane Database Syst Rev. 2013;8:CD006102.

64. Johnson JG, Cohen P, Pine DS, Klein DF, Kasen S, Brook JS. Association between cigarette smoking and anxiety disorders during adolescence and early adulthood. JAMA 2000;284:2348-51.

65. George TP, Wu BS, Weinberger AH. A review of smoking cessation in bipolar disorder: implications for future research. J Dual Diagn 2012;8:126-30.

66. Weinberger AH, Vessicchio JC, Sacco KA, Creeden CL, Chengappa KN, George TP. A preliminary study of sustained-release bupropion for smoking cessation in bipolar disorder. J Clin Psychopharmacol 2008;28:584-7.

67. Wu BS, Weinberger AH, Mancuso E, et al. A preliminary feasibility study of varenicline for smoking cessation in bipolar disorder. J Dual Diagn 2012;8: 131-2.

68. Heffner JL, Anthenelli RM, DelBello MP, Stahl L, Strakowski SM. Mood management and nicotine patch for smoking cessation in adults with bipolar disorder. Nicotine Tob Res 2013;15:1805-6.

69. Evins AE, Cather C, Pratt SA, et al. Maintenance treatment with varenicline for smoking cessation in patients with schizophrenia and bipolar disorder: a randomized clinical trial. JAMA 2014;311:145-54.

70. Tsoi DT, Porwall M, Webster AC. Interventions for smoking cessation and reduction in individuals with schizophrenia. Cochrane Database Syst Rev 2013;2: CD007253.

71. Bullen C, Howe C, Laugesen M, et al. Electronic cigarettes for smoking cessation: a randomised controlled trial. Lancet 2013;382:1629-37.

72. Fairchild AL, Bayer R, Colgrove J. The renormalization of smoking? E-cigarettes and the tobacco “endgame". N Engl J Med 2013;370:293-5.

73. Zevin S, Benowitz NL. Drug interactions with tobacco smoke: an update. Clin Pharmacokinet 1999; 36:425-38. 